UDC 349.6:504

LBC 67.407 .07

\title{
ENVIRONMENTAL TERRORISM AS A GLOBAL PROBLEM OF MODERN TIMES
}

\author{
Anatoliy Ya. Ryzhenkov \\ Volgograd State University, Volgograd, Russian Federation
}

\begin{abstract}
Introduction: the problem of counteraction to terrorism is one of the most urgent and discussed global problems of present times. Now hundreds of international acts devoted to the fight against the international terrorism which use the most diverse arsenal of means and ways of the fight against this global threat of present times are adopted. However, so far, the specifics of ecological terrorism have been investigated obviously insufficiently. In the work the author sets the research objective - carrying out the classification of types of ecological terrorism. Methods: the methodological framework of the research includes a set of methods of scientific knowledge, among which the main are the methods of system analysis, historicism, and the comparative law method. Results: the work proves the author's position on the existence of four kinds of ecological terrorism. It is proved that ecological terrorism involves not only the practice of violence and intimidation of the population by environmental pollution for having impact on decision-making by the public bodies, but also a special ideology. In this connection, for the effective counteraction to this global threat of the 21 st century, the measures of ideological (information) counteraction are also required. Conclusions: it is necessary to adopt at the international level under the UN guidance the regulations sustained in one terminology which does not allow identifying ordinary terrorists with ecological radical youth groups who are seldom beyond penal hooliganism or deliberate destruction of someone else's property in their illegal activity. It is also required to create a more accurate classification of types of ecological terrorism in terms of which it is suggested distinguishing nuclear, technological, chemical and biological terrorism, having both a number of general features and methods of fight against them, and the peculiar specifics demanding further studying and prevention.
\end{abstract}

Key words: ecological terrorism, environment, conventions, safety, cooperation, technologies.

УДК 349.6:504

ББК 67.407 .07

\section{ЭКОЛОГИЧЕСКИЙ ТЕРРОРИЗМ КАК ГЛОБАЛЬНАЯ ПРОБЛЕМА СОВРЕМЕННОСТИ}

\author{
Анатолий Яковлевич Рыженков \\ Волгоградский государственный университет, г. Волгоград, Российская Федерация
}

\begin{abstract}
Введение: проблема противодействия терроризму является одной из самых актуальных и обсуждаемых глобальных проблем современности. В настоящее время приняты сотни международных актов, посвященных борьбе с международным терроризмом, которые используют самый различный арсенал средств и способов борьбы с этой глобальной угрозой современности. Однако специфика экологического терроризма до сих пор исследована явно недостаточно. В работе поставлена цель исследования - проведение классификации видов экологического терроризма. Методы: методологическую основу данного исследования составляет совокупность методов научного познания, среди которых основное место занимают методы системного анализа, историзма и сравнительно-правовой метод. Результаты: в работе обоснована авторская позиция о существовании четырех разновидностей экологического терроризма. Доказывается, что экологический терроризм представляо ㄹ собой не только практику насилия и устрашения населения путем загрязнения окружающей среды в целях оказания воздействия на принятие решений органами публичной власти, но и специальную идеологию, в связи с чем для эффективного противодействия этой глобальной угрозе XXI века наряду с другими требуются и () меры идеологического (информационного) противодействия. Выводы: необходимо принятие на междуна-
\end{abstract}


родном уровне под руководством ООН нормативных актов, выдержанных в одной терминологии, не допускающей отождествления обычных террористов с экологическими радикальными молодежными группировками, редко выходящими в своей противоправной деятельности за рамки уголовно наказуемого хулиганства или умышленного уничтожения чужого имущества. Требуется и более четкая классификация видов экологического терроризма, в рамках которой предлагается выделение ядерного, технологического, химического и биологического терроризма, обладающих как рядом общих признаков и методов борьбы с ними, так и особой спецификой, требующей дальнейшего изучения и профилактики.

Ключевые слова: экологический терроризм, окружающая среда, конвенции, безопасность, сотрудничество, технологии.

\section{Введение}

Проблема противодействия терроризму является одной из самых актуальных и обсуждаемых глобальных проблем современности. В настоящее время приняты сотни международных актов, посвященных борьбе с международным терроризмом, которые используют самый различный арсенал средств и способов противодействия этой глобальной угрозе современности. Однако все они до сих пор не привели к окончательному решению данной проблемы. Этому вопросу посвящены тысячи научных работ, в которых проведен глубокий анализ причин появления терроризма как мирового явления, влияния на динамику его развития, разрыва в уровне жизни бедных и богатых стран, появления новых радикальных религиозных учений и т. д. Не пытаясь воспроизводить все эти наработки, определим задачу данной статьи более локально: сформулировать определение экологического терроризма и его отличий от смежных правовых явлений, а также предложить ряд мер противодействия данной угрозе.

Важность проведения подобных исследований заключается в том, что с каждым годом растет число удачных и неудачных попыток проведения террористических актов, связанных с воздействием на окружающую среду. В числе совершенных актов экологического терроризма можно, например, назвать распыление в Японии газа зарин террористической организацией «Аум Сенрике» в токийском метро, хотя, по счастью, большая часть терактов по тем или иным причинам не состоялась (например, попытка подрыва террористами 21 июля 2010 г. Баксанской ГЭС в Республике Кабардино-Балкария; размещение чеченскими террористами контейнера с радиоактивным цезием-137 в Измайловском парке г. Москвы в 1995 г. и т. д.). Отсюда следует необходимость анализа международных и национальных правовых актов, положений научной доктрины и правоприменительной практики, посвященных профилактике и/или путям преодоления последствий экологического терроризма, в целях выработки дальнейших рекомендаций по повышению эффективности противодействия данной угрозе в условиях первой четверти XXI века.

\section{Основное содержание понятия «экологический терроризм»}

В настоящий момент сохраняется терминологическая проблема, связанная с пониманием в различных странах мира сущности экологического терроризма. В США и некоторых других государствах под экологическим терроризмом (ecoterrorism) часто понимается деятельность радикальных групп экологов, осуществляющих нападения на научно-исследовательские учреждения (в целях «освобождения» экспериментальных животных), рестораны или лесозаготовительные компании, а также на отдельных граждан (например, в целях уничтожения их автотранспорта или шуб, изготовленных из меха животных).

Наиболее известны такого рода «противоправной активностью» члены Фронта освобождения животных (ALF), которые выступают против использования животных в медицинских экспериментах, а также Фронта освобождения Земли (ELF), защищающего путем насилия природную среду от уничтожения и эксплуатации. Наиболее крупные акции ELF - поджоги горнолыжного курорта в Вейле (1996 г.), бюро по управлению земельными ресурсами в штате Орегон (1997 г.), жилого комплекса в Сан-Диего, штат Калифорния (2003 г.) [6, с. 107]. 
Между тем молодежные радикальные экологические группировки необходимо отличать от «классических террористов», поскольку они преследуют совершенно разные цели, а потому с указанными явлениями должны применяться и различные методы борьбы. В отличие от радикальных «мер борьбы» молодежных группировок, редко выходящих за рамки уголовно наказуемого хулиганства или умышленного уничтожения чужого имущества, экологический терроризм, имеющий довольно существенную специфику, тем не менее является разновидностью террористической деятельности и имеет все ее признаки.

В числе таких общих признаков выделим цель террористов по устрашению (запугиванию) населения, насильственные методы террористов, наличие у них определенной идеологии и пропаганду ее путем совершения террористических актов, попытки воздействия на действия (бездействие) органов публичной власти или иных субъектов. К числу же специальных признаков только экологического терроризма следует отнести объект воздействия - благоприятное качество окружающей среды, которому наносится ущерб. Исходя из такого определения экологического терроризма и его признаков необходимо отграничивать его от смежных явлений, включая экоцид или ведение «экологических войн».

В частности, последняя проблема начала постепенно разрешаться после принятия Конвенции о запрещении военного или любого иного враждебного использования средств воздействия на природную среду от 10 декабря 1976 года. Данная Конвенция устанавливает, что государства - участники Конвенции обязуются не прибегать к военному или любому иному враждебному использованию средств воздействия на природную среду, которые имеют широкие, долгосрочные или серьезные последствия, в качестве способов разрушения, нанесения ущерба или причинения вреда любому другому государству - участнику Конвенции. Из этого следует, что в сферу действия данной Конвенции попадают случаи, когда одно или несколько государств ведут боевые действия друг с другом, при этом обязуются держать свои вооруженные силы в определенных экологически обусловленных рамках. В случае же с экологически- ми террористами субъектом причинения вреда жизни, здоровью и имуществу граждан выступает отдельный террорист или их группа, не связанная с конкретным государством, пропагандирующая свои политические, религиозные или иные идеи.

Причинами появления экологического терроризма являются повышение значимости экологической безопасности в системе ценностей современного мирового сообщества, рост числа экологически опасных объектов (например, атомных электростанций), а также научно-технический прогресс, упрощающий доступ террористов к различным экологически опасным веществам или технологиям их изготовления, к чему ведет развитие сети Интернет.

При этом, несмотря на очевидную угрозу экологического терроризма, данное явление не получило однозначной дефиниции в научных правовых исследованиях. Так, например, С.В. Иванцов предлагает определение экологического терроризма как незаконного или умышленного причинения серьезного ущерба окружающей среде с целью устрашения и запугивания населения или принуждения правительства или международной организации к совершению каких-либо действий или воздержанию от их совершения [4].

Д.И. Тисленко полагает, что экологический терроризм - это имеющие повышенную общественную опасность идеология и практика насилия, устрашающего население и совершаемого путем загрязнения окружающей среды, в том числе в целях привлечения внимания к определенным взглядам либо для воздействия на принятие решения (совершение действия/бездействия) органом власти, органом местного самоуправления, международной организацией, юридическим лицом, социальной группой, физическим лицом [9, с. 9].

Таким образом, авторы подчеркивают главные отличительные черты экологического терроризма, связанные с устрашением, запугиванием населения и принуждением органов власти к принятию определенных решений. При этом в первом определении автор использует оценочную категорию «существенный ущерб» окружающей среде, требующую специального толкования, а во второй дефиниции предполагается воздействие тер- 
рористов на принятие решений не только органом публичной власти, но и юридическим лицом и социальной группой (при юридической расплывчатости понимания последней), что представляется дискуссионным. В остальном определение Д.И. Тесленко не вызывает возражений и может быть признано наиболее удачным.

\section{Классификация видов экологического терроризма}

Исходя из существующих представлений об экологическом терроризме попытаемся сформулировать примерную классификацию его разновидностей и особенностей:

1. На ядерный терроризм как глобальную угрозу современности мировое сообщество впервые обратило внимание в 1960 1970-е годы. Именно тогда в ООН были высказаны предложения о принятии международно-правовых актов, направленных на предотвращение данной угрозы. С тех пор разработкой таких документов занимается главным образом Международное агентство по атомной энергии, разработавшее, в частности, Конвенцию о физической защите ядерного материала (Вена, 26 октября 1979 г.). Впоследствии вопросы противодействия ядерному терроризму продолжали оставаться в центре внимания, что было отражено в ряде международных и национальных правовых актов.

Объективной предпосылкой совершения террористических актов с применением ядерного оружия или соответствующих технологий является несовершенство системы контроля за расщепляющимися материалами, поскольку в сферу обращения с радиоактивными материалами вовлечены тысячи специалистов и лиц вспомогательного персонала, что значительно увеличивает уязвимость систем их охраны. Среди других факторов в научной литературе отмечаются распространение ядерных технологий за пределы границ традиционных ядерных держав; недостаточная эффективность охраны границ между государствами, таможенного контроля, сотрудничества государств и их специально уполномоченных органов по борьбе с незаконным оборотом радиоактивных материалов; большие прибыли преступных организаций, позволяю- щие им финансировать свои программы создания ядерных взрывных устройств; открытость специальной литературы, позволяющей осуществлять деятельность по изготовлению ядерных взрывных устройств. Наряду с этим далеко не во всех странах непосредственная защита ядерных объектов (атомных электростанций, судов с ядерными реакторами), мест размещения радиоактивных отходов и материалов находится на должном уровне. Указанные обстоятельства создают предпосылки для реализации преступных замыслов террористов. Особая опасность актов ядерного терроризма может быть объяснена еще и тем обстоятельством, что в результате их совершения возможны большие человеческие жертвы, а также экологические катастрофы. Именно поэтому Совет Безопасности $\mathrm{OOH}$ в своей резолюции от 28 сентября 2001 г. № 1373 (2001) специально подтвердил, что действия террористов в США, как и любой акт международного терроризма, представляют собой угрозу для международного мира и безопасности [5, с. 3-4].

Между тем официальная точка зрения на угрозу совершения актов ядерного терроризма несколько отличается от доктринального подхода. В частности, генеральный директор Международного агентства по атомной энергии (МАГАТЭ) отмечал, что хищение ядерного оружия либо попадание в руки террористов средств и информации для производства ядерного взрывного устройства маловероятно. Куда большую угрозу представляет воздействие на людей и окружающую среду «грязной бомбы» (созданной с использованием радиоактивных отходов), приведенной в действие с помощью обычного взрывного устройства. Сохраняется ряд проблем с определением степени ядерной террористической угрозы в условиях сотен подтвержденных случаев незаконного провоза ядерных материалов, которые потенциально могут быть использованы для совершения террористических актов. Имеется и неопределенность в отношении статуса таких материалов в государствах, являющихся известными обладателями ядерного оружия [2]. В связи с этим в научной литературе предложено понимать под «ядерным терроризмом» использование или угрозу использования в террористической де- 
ятельности ядерных взрывных устройств (самодельных или штатных военных боеприпасов различного назначения), а также радиоактивных материалов в целях радиоактивного заражения объектов, местности, водоемов, воздуха, а равно разрушение (повреждение, захват) ядерных объектов [10, с. 42-49]. С данным подходом следует полностью согласиться.

\section{2. Технологический терроризм так-} же находится в центре внимания международного сообщества, сопровождаясь принятием ряда международных документов. Так, в Договоре «О сотрудничестве государств - участников Содружества Независимых Государств в борьбе с терроризмом» (Минск, 4 июня 1999 г.) выделены «объекты повышенной технологической и экологической опасности», под которыми понимаются «предприятия, сооружения, установки и другие объекты, выведение из строя которых может привести к гибели людей, причинению ущерба здоровью населения, загрязнению окружающей среды либо дестабилизации положения в конкретном регионе или конкретном государстве в целом». При этом кроме «мер оперативного, информационного или координационного характера» особо оговаривается обязанность стран - участниц договора оказывать друг другу содействие в части оценки состояния системы физической защиты объектов повышенной технологической и экологической опасности, разработке и реализации мер по совершенствованию данной системы. Оговариваются также вопросы финансирования научно-исследовательских и опытно-конструкторских работ по разработке систем и средств физической защиты объектов повышенной технологической и экологической опасности.

В Рекомендациях по совершенствованию законодательства государств - участников СНГ в сфере противодействия технологическому терроризму (принятых в Санкт-Петербурге 16 апреля 2015 г. на 42-м пленарном заседании Межпарламентской ассамблеи государств - участников СНГ) было предложено произвести распределение потенциально опасных технологий на группы (категории) по уровню потенциальной опасности для человека и окружающей среды в соответствии с рекомендациями компетентных международных орга- низаций и основополагающими международными документами, а также предложен ряд терминов и мер по обеспечению безопасности опасных объектов.

3. Реальностью сегодняшнего дня стала проблема химического терроризма, примером чему является уже упомянутая ранее атака, предпринятая боевиками секты «Аум Сенрике» в 1995 г. в токийском метро. Поскольку изготовление опасных для жизни и здоровья химических веществ намного проще, чем, например, ядерных взрывных устройств, в современных условиях угроза химического терроризма значительно возрастает. Не исключено и появление новых форм и методов террористических действий, которые могут привести к многочисленным человеческим жертвам. К числу таких форм и методов может быть отнесено отравление продуктов питания, водных объектов, лекарственных препаратов, воздуха в зданиях, метро и других подземных сооружениях, транспортных средствах, заражение атмосферного воздуха в населенных пунктах и т. д. Полностью устранить данную угрозу, все чаще обсуждаемую в контексте продолжающейся много лет войны в Сирии, путем разработки поправок к Конвенции о запрещении разработки, производства, накопления и применения химического оружия и его уничтожении от 13 января 1993 г. невозможно, поскольку в данной Конвенции предусмотрена слишком сложная процедура принятия изменений и дополнений. Более реалистичным и перспективным средством борьбы с угрозой химического терроризма представляется разработка отдельной конвенции по борьбе с актами химического терроризма.

4. Биологический терроризм долгое время рассматривался как менее вероятная угроза, чем химический или технологический терроризм, главным образом по причине сложности приобретения культур бактерий или получения их в домашних условиях. Распространение спор сибирской язвы в США осенью 2001 г. опровергло это мнение. Условиями, повышающими реальность данной угрозы, являются развитие биотехнологий и достижения генной инженерии; наличие значительного числа специалистов, способных создать биооружие, а также сложность массовой защиты общества в случае применения такого оружия. 
Как отмечалось в научной литературе, к возможным типам биологического оружия «могут относиться различные биорегуляторы, воздействующие на жизненно важные функции и системы организма, а также этническое оружие, действие которого основано на генетических и иммунологических особенностях разных этнических групп людей. Расшифровка геномов животных и растений в сочетании со сведениями о биологическом разнообразии конкретных регионов может открыть способ воздействия на экономически важные виды животных и сорта растений, а это, в свою очередь, способно спровоцировать появление еще одной формы террористической активности - агротерроризма» [3, с. 49].

Одним из факторов, снижающих эффективность противодействия биологическому терроризму, является слабая теоретико-правовая база борьбы с исследуемым общественно опасным явлением, равно как и ее непосредственное международно-правовое регулирование. До настоящего дня не был принят специальный международно-правовой акт, регулирующий вопросы противодействия биологическому терроризму. Без развития международно-правовых основ противодействия данной угрозе невозможно эффективное сотрудничество и взаимодействие стран по борьбе с угрозой биологического терроризма $[7$, c. 4-5].

Следует согласиться с тем, что биотерроризм - международное преступление, «представляющее угрозу международному миру и безопасности человечества, состоящее в умышленном действии или бездействии по высвобождению, рассеиванию или распространению биологических агентов или токсинов либо по созданию условий для их высвобождения, рассеивания или распространения, в результате которых причиняется вред жизни и здоровью людей, сельскохозяйственных животных или культурных растений либо создается угроза причинения такого вреда, совершенные с целью устрашения населения, нарушения общественной безопасности и оказания воздействия на принятие решения органами власти государств или международными организациями; угрозе совершения указанных деяний в тех же целях; соучастии в совершении указанных деяний в качестве орга- низатора, соисполнителя, подстрекателя или пособника; приготовлении или покушении на совершение указанных деяний» [7, с. 18].

Существует несколько вариантов совершения актов биотерроризма, выделяемых по критерию возможных последствий: а) медицинские - заболевание людей и животных и их смерть; б) экономические - уменьшение количества трудоспособного населения, остановка или сокращение объемов промышленного производства, ущерб агропромышленному комплексу страны; в) социальные - массовая паника и страх, нарушение традиционного уклада жизни населения или социальных групп, массовый голод, увеличение числа социальных конфликтов и массовых волнений; г) политические - подрыв легитимности государственной власти, дезорганизация работы государственного механизма, активизация протестных выступлений политической оппозиции; д) военные - вывод из строя живой силы противника, снижение боеспособности вооруженных сил, нарушение управления военной организацией государства [7, с. 20].

\section{Основные меры по борьбе с терроризмом}

Меры противодействия каждому виду терроризма могут иметь свою специфику, однако их общей чертой будет усиление международного сотрудничества в борьбе со всеми разновидностями экологического терроризма, включая информационный обмен, контроль за специальными технологиями, которые могут быть использованы террористами для негативного воздействия на окружающую среду, жизнь и здоровье граждан, разработка мер по преодолению последствий актов экологического терроризма, если они все-таки состоялись.

В качестве еще одной из официально признаваемых мер по борьбе с терроризмом является усиление эффективности международного правосудия. $\mathrm{OOH}$ неоднократно указывала, что борьба с международным терроризмом получит новый импульс, если совершенные террористами преступления будут рассматриваться Международным уголовным судом и подвергаться преследованию на основании его Статута (при условии, что соответствующий национальный суд не может или 
не хочет осуществлять такое преследование). Поскольку Статут включает категорию преступлений против человечности, куда входят убийства и истребления, совершенные в рамках широкомасштабного или систематического нападения на любых гражданских лиц, определенные террористические акты могут преследоваться на основании Статута [2]. Данная мера получила поддержку и в научной литературе [8, с. 54]. Между тем ее эффективность вызывает сомнения. Признавая большую роль правосудия в работе по противодействию экологическому терроризму, в данном случае мы не достигнем «нового импульса» в борьбе с международным терроризмом, так как рассмотрение таких категорий дел Международным уголовным судом вряд ли станет массовым, поскольку в большинстве случаев террористы являются смертниками.

Намного более эффективным представляется необходимость выработки более сложного комплекса мер, выходящих за рамки собственно правовой науки. В числе таких мер следует отметить идеологические, экономические, социальные и другие меры борьбы с экологическим терроризмом. Так, требуют усиления меры по идеологическому противодействию экологическому терроризму, все имевшиеся случаи которого были связаны с посягательством на фундаментальное право человека, закрепленное в международных актах и конституциях всех стран мира, - право на благоприятную окружающую среду [1].

Представляется, что необходимо выделить две группы таких идеологических мер:

Во-первых, четкое отделение экологического терроризма от деятельности радикальных экологических групп (обычно молодежных), связанных с борьбой за права животных или иные экологические ценности (иногда весьма необычно понимаемые). Таких радикалов в зарубежном законодательстве и научной доктрине часто именуют «экологическими террористами», затрудняя тем самым борьбу с более серьезной угрозой, именуемой аналогичным термином. В отличие от обычных террористов, с молодыми экологическими радикалами можно вести диалог и даже учитывать в нормотворчестве их отдельные идеи (например, в части прав животных или гуманного к ним отношения).
Во-вторых, необходимо усиление роли $\mathrm{OOH} \mathrm{и} \mathrm{других} \mathrm{международных} \mathrm{организаций} \mathrm{в}$ противодействии непосредственно экологической разновидности более общей террористической угрозы, имеющей свою довольно существенную специфику. С помощью принятия конвенций, резолюций, заявлений и иных мер $\mathrm{OOH}$, как наиболее авторитетная в современном мире международная организация, сможет сделать свой вклад в профилактику и сдерживание недовольства многочисленных социальных и религиозных групп, для того чтобы они не становились на путь терроризма, а тех, кто способствует или потворствует террористическим актам, - от сохранения связей и симпатий к террористам. Универсальный характер, глобальный охват и международная легитимность $\mathrm{OOH}$ являются тем весьма важным активом, на который она может опереться в ходе осуществления таких мер по идеологическому (информационному) противодействию терроризму. Многие из существующих программ ООН могли бы способствовать тому, чтобы сделать терроризм непривлекательным и сократить людские, материальные и финансовые ресурсы, которые его подпитывают.

В рамках данной деятельности $\mathrm{OOH}$ большую роль играют меры по развитию экологического образования, просвещения и воспитания, которые могли бы более широко проводиться в развивающихся странах. И хотя сами по себе данные меры не способны предотвратить совершение террористического акта, в комплексе с другими правоохранительными, финансовыми, техническими и иными мерами они могут внести свой вклад в решение этой проблемы.

\section{Выводы}

Экологический терроризм представляет собой не только практику насилия и устрашения населения путем загрязнения окружающей среды в целях оказания воздействия на принятие решений органами публичной власти, но и специальную идеологию, в связи с чем для эффективного противодействия этой глобальной угрозе XXI в. наряду с другими требуются и меры идеологического (информационного) противодействия. Необходимо принятие на 
международном уровне под эгидой ООН нормативных актов, выдержанных в одной терминологии, не допускающей отождествления обычных террористов с экологическими радикальными молодежными группировками, редко выходящими в своей противоправной деятельности за рамки уголовно наказуемого хулиганства или умышленного уничтожения чужого имущества. Требуется и более четкая классификация видов экологического терроризма, в рамках которой предлагается выделение ядерного, технологического, химического и биологического терроризма, обладающих как рядом общих черт и методов борьбы с ними, так и особой спецификой, требующей дальнейшего изучения и профилактики.

\section{СПИСОК ЛИТЕРАТУРЫ}

1. Анисимов, А. П. Право человека и гражданина на благоприятную окружающую природную среду (конституционно-правовые аспекты) : автореф. дис. ... канд. юрид. наук / Анисимов Алексей Павлович. - Волгоград, 1997. - 30 с.

2. Доклад Рабочей группы по разработке политики по вопросу о роли Организации Объединенных Наций в связи с терроризмом : (принят в г. Нью-Йорке 31 июля 2002 г. на 57-й сессии Генер. Ассамблеи ООН). - Доступ из справ.-правовой системы «КонсультантПлюс» (дата обращения: 16.02.2017).

3. Жалыбин, С. В. Юридическая институционализация современной российской антитеррористической политики : дис. ... канд. юрид. наук / Жалыбин Сергей Викторович. - Ростов н/Д, 2006. $165 \mathrm{c}$.

4. Иванцов, С. В. Экологический терроризм как новое проявление современной организованной преступной деятельности / С. В. Иванцов // «Черные дыры» в российском законодательстве. 2008. - № 1. - С. 189-192.

5. Косачев, К. И. Концепция развития международного права в области борьбы с ядерным терроризмом : автореф. дис. ... канд. юрид. наук / Косачев Константин Иосифович. - М., 2003. - 24 с.

6. Овчинский, В. С. Экстремистские организации в США / В. С. Овчинский, М. А. Кочубей // Журнал российского права. - 2009. - № 6. - С. 101-113.

7. Симонова, А. Е. Международно-правовые аспекты борьбы с биотерроризмом : автореф. дис. ... канд. юрид. наук / Симонова Александра Евгеньевна. - М., 2007. - $26 \mathrm{c}$.

8. Синякин, И. И. Терроризм с использованием оружия массового уничтожения: международ- но-правовые вопросы противодействия / И. И. Синякин. - М. : Норма, 2012. - 192 с.

9. Тисленко, Д. И. Экологический терроризм: уголовно-правовые и криминологические проблемы : автореф. дис. ... канд. юрид. наук / Тисленко Дмитрий Игоревич. - Саратов, 2012. - 27 с.

10. Хлобустов, О. М. О некоторых понятиях и терминах в сфере борьбы с современным терроризмом / О. М. Хлобустов // Российский следователь. -2006 . - № 5. - С. 42-49.

\section{REFERENCES}

1. Anisimov A.P. Pravo cheloveka $i$ grazhdanina na blagopriyatnuyu okruzhayushchuyu prirodnuyu sredu (konstitutsionno-pravovye aspekty): avtoref. dis. ... kand. yurid. nauk [The Right of a Human and a Citizen to the Favorable Environment (Constitutional and Legal Aspects). Cand. jurid. sci. abs. diss.]. Volgograd, 1997.30 p.

2. Doklad Rabochey gruppy po razrabotke politiki po voprosu o roli Organizatsii Obyedinennykh Natsiy v svyazi s terrorizmom: (prinyat v g. Nyu-Yorke 31 iyulya 2002 g. na 57-y sessii Gener. Assamblei OON) [The Report of the Working Group on Development of Policy on the Role of the United Nations in Connection with Terrorism: (adopted in New York on July 31, 2002 at the 57th session of the United Nations General Assembly)]. Access from KonsultantPlyus reference legal system.

3. Zhalybin S.V. Yuridicheskaya institutsionalizatsiya sovremennoy rossiyskoy antiterroristicheskoy politiki: dis. ... kand. yurid. nauk [Legal Institutionalization of Modern Russian Anti-Terrorist Policy. Cand. jurid. sci. diss.]. Rostov-on-Don, 2006. 165 p.

4. Ivantsov S.V. Ekologicheskiy terrorizm kak novoe proyavlenie sovremennoy organizovannoy prestupnoy deyatelnosti [Ecological Terrorism as New Manifestation of Modern Organized Criminal Activity]. «Chernye dyry» $v$ rossiyskom zakonodatelstve, 2008, no. 1, pp. 180-182.

5. Kosachev K.I. Kontseptsiya razvitiya mezhdunarodnogo prava voblasti borby s yadernym terrorizmom: avtoref. dis. ... kand. yurid. nauk [The Conception of International Law Development in the Field of Nuclear Terrorism Prevention. Cand. jurid. sci. abs. diss.]. Moscow, 2003. 24 p.

6. Ovchinsky V.S., Kochubey M.A. Ekstremistskie organizatsii v SShA [The Extremist Organizations in the USA]. Zhurnal rossiyskogo prava, 2009, no. 6, pp. 101-113.

7. Simonova A.E. Mezhdunarodno-pravovye aspekty borby s bioterrorizmom: avtoref. dis. ... kand. yurid. nauk [International Legal Aspects of 
Bioterrorizm Prevention. Cand. jurid. sci. abs. diss.]. Moscow, 2007. $26 \mathrm{p}$.

8. Sinyakin I.I. Terrorizm s ispolzovaniem oruzhiya massovogo unichtozheniya: mezhdunarodno-pravovye voprosy protivodeystviya [Terrorism with Use of Mass Destruction Weapon: International Legal Questions of Counteraction]. Moscow, Norma Publ., 2012. 192 p.

9. Tislenko D.I. Ekologicheskiy terrorizm: ugolovno-pravovye i kriminologicheskie problemy: avtoref. dis. ... kand. yurid. nauk [Ecological Terrorism: Criminal and Legal and Criminological Problems. Cand. jurid. sci. abs. diss.]. Saratov, 2012. $27 \mathrm{p}$.

10. Khlobustov O.M. O nekotorykh ponyatiyakh i terminakh v sfere borby s sovremennym terrorizmom [On Some Concepts and Terms in the Sphere of Fight against Modern Terrorism]. Rossiyskiy sledovatel, 2006, no. 5, pp. 42-49.

\section{Information about the Author}

Anatoliy Ya. Ryzhenkov, Doctor of Juridical Sciences, Professor, Department of Civil and International Private Law, Volgograd State University, the Base Department of the Southern Scientific Center of the Russian Academy of Sciences, Prosp. Universitetsky, 100, 400062 Volgograd, Russian Federation,4077778@list.ru, gimchp@volsu.ru.

\section{Информация об авторе}

Анатолий Яковлевич Рыженков, доктор юридических наук, профессор кафедры гражданского и международного частного права, Волгоградский государственный университет, базовая кафедра ЮНЦ РАН, просп. Университетский, 100, 400062 г. Волгоград, Российская Федерация,4077778@list.ru, gimchp@volsu.ru. 